\title{
Effective Implementation of Portals: Best Practice Model
}

\author{
Abdullah S. Al-Mudimigh \\ Department of Information System, College of computer and Information Sciences \\ King Saud University, Saudi Arabia \\ E-mail: mudimigh@ksu.edu.sa \\ Zahid Ullah \\ Department of Information System, College of computer and Information Sciences \\ King Saud University, Saudi Arabia \\ E-mail: zahid@ksu.edu.sa
}

\begin{abstract}
Portals are the gateways that integrate the information from different sources in a single window and provide it to the end users. Portal implementation is a very intricate job as it requires a significant amount of resources and knowledge to invest. However portals have the ability to improve the status and ranking of an enterprise to the best of the customer satisfaction and employees moral. On the basis of these motivations we have proposed a model for the complete implementation and services delivery of portals. The model has two parts that describe the overall performance and the entire framework of the portal implementation. Finally the proposed model is an iterative model that can proudly accept changes at any stage of its implementation.
\end{abstract}

Keywords: Portal framework, Implementation model, Services, Support \& Management

\section{Introduction}

Rapid changes in the internet technology can urge significant challenges in the business of an organization. New services are always required to make the portal more effective and valuable according to the organization's need and employees moral. Portals are ongoing projects and need modification time to time. Many researchers have risen up this issue and have expressed their views of portal implementation and proposed implementation model from different angles. In this paper we have proposed a model for complete portal implementation. The model consists of two different stages. The first model is for the complete portal implementation while the second one is for service delivery. We have described the steps of our model for the complete implementation of portal for the success of an organization in the following sections. The rest of the paper is schedule as: section 2 will describe literature review, methodology has described in section 3 and section 4 consists of portal framework. Finally the last part of this paper has conclusion and future work.

\section{Background Study/Literature Review}

The literature reviewed for this paper has been referenced from different journals and articles related to the topic of this paper. Portals are the gateways that collect the information from many sources and provide it to the end users on a single window (Caro. A., Calero. C., Mendes. E., \& Piattini. M., 2007), (Rahim. M. M., 2007), (Davydov, M. M., 2001). Portals development is a costly initiative and not only that it costs the company to develop it but it requires significant business process change in order to influence it for business benefits (Chan. M.F.S., \& Chung. W.W.C., 2002). Zhu et-al (2004) has implemented an informative portal which has a unique characteristics and functions for the educational sectors. Hazra (2002) described the software engineering principles for the implementation and challenges face the enterprise portal. According to Deltor (2000) corporate portals offer organizational users the ability to access a wide variety of information sources directly from the desktop. Senior business executive appreciate portal's ability on the delivery of benefits to the organization and their employees (Tojib, D. R., Sugianto, L. F., \& Rahim, M. M., 2005). The organizations are needed to exclude all the inaccurate and misleading information and provide the right information to the right people (Parker. R.C., 1997). Georgia et-al (2010) proposed a model for portal implementation that integrates a great deal of functionality that is exited on the web or services. Yon et-al (2008) described a model that converts a tacit knowledge into explicit knowledge. 


\section{Methodology}

The developing and maintaining of portals is not similar to developing and delivering services within the portal itself. Usually, when developing or maintaining the portal, there will be enough time and space to do that. While in developing and delivering new services and application to the portal may needs some special treatment and limitations such as time limit, integration plan, impact analysis and prioritization of the requested services. We assure that a portal implementation is a separate and intricate project that aims to develop the overall portal and its functionalities. On the basis of these motivations we have presented a model for the complete portal implementation and service delivery. In this paper the proposed model is divided into two complimentary models. The first one is the complete portal implementation model as shown in figure 1 while the second one that is the part of the first model is more concerning about service delivery as shown in figure 3 .

\section{Framework of our Portal}

This framework consists of five general steps shown in figure 2.

\subsection{Benchmarking and requirements gathering}

In this stage the organization should do some important benchmarking to other similar portal implementations that fits the organization's culture and domain. For instance if the organization is an educational institute they must benchmark similar and high quality of the educational portal implementations. Requirements gathering are very important to benchmark the implemented portal because every organization has their unique requirements. This step helps in defining the requirements and gives a general overview of how the portal will look like and will define the functionalities and services that the portal will provide. Gathering the requirements will specify the organization own needs besides there is no one portal implementation that fits all organizations. Finally, requirements gathered must be actionable, measurable, testable and related to the overall business needs and objectives. It is strongly recommended to start this phase after taking full support from the top management.

\subsection{Analysis}

It simply means that analyzing the requirements that we have gathered in the first step. This step defines the plan that which part of information is more important for the instant implementation and which information will be implemented later and also it is used to identify any possible conflict in requirements. Furthermore, some requirements may cause such changes in the nature of the organization that will need "Business Process Reengineering" before proceeding.

\subsection{Designing}

In the design phase of portal implementation we are going to plan for the successful portal implementation. In the planning of this implementation a business case is conducted and make the decision to develop or buy the portal package by defining the portal integration architecture or define the taxonomy of the portal and also decide that what functionalities will be implemented (Remus, U., 2006).

\subsection{Implementation}

It is simply implementing what we defined and planed in the previous three phases. Project management plays a key role in implementation. In implementation the actual portal will be delivered after the intensive testing must be done according to test cases.

\subsection{Introduction and User Acceptance}

Finally, the fifth phase in our model is "Introduction and User Acceptance". Now the portal can be introduced to stakeholders as well as its services and functionalities. Only now we can get there acceptance to introduce the new portal to the main user group either they are public or private user groups. More important, this phase is the most challenging phase in the model since without acceptance no portal will be used.

Additionally, it is important to know that proposed model is an iterative model. We can repeat these loops as many times as we need till the final decision of an organization and end users. For instance if the stakeholders are not satisfied by the end product so we may go back to the first phase "Requirement Gathering", similarly if the organization is facing any problem in "Implementation" so we can make changes in designing. Finally we can proudly say that we have implemented the portal successfully. But unfortunately that is not happening at all because portal projects are continuous and never ending project as long the organization exist the portal project will continue. To overcome this limitation we have proposed another model which is described in the following sections and the model is shown in figure 3 (Service delivery model). 


\section{Service Delivery Model}

As mentioned in the paper that portal projects are ongoing projects and never ends for that reason we have proposed the second model as shown in figure 3. This model represents a service delivery life cycle that is a continuance process of figure 1 . The model shown in figure 3 should be applied for every service request after the introduction of the new portal. These services will improve the portals functionalities and the overall services that it provides. This model has been adapted from Hazra (2002) component based approach as well as ITIL V3 IT (SMF., 2007) best practices in Service Delivery.

\subsection{Steps in Service Delivery Model}

The following steps are used in the service delivery life cycle as shown in figure 3.

\subsubsection{Initiation}

This step usually comes from the business side of the organization and can be driven by tactical or strategic objectives [6]. Moreover, the business must specify what exactly are the services, the need of these services, why they need these services and when do they need it. This initiation can be request for a new service or a change in an existing service.

\subsubsection{Evaluation}

This is very important step and the scope of work will be defined here. This is like a contract between the business and IT and more important that the acceptance of users will be based directly on the scope of work. Impact analysis document will be provided during the evaluation. This document will describe what impact the new services will put to the existing services and define dependency that exists between them. Moreover, risk identification document should be present at this stage and it should describe what type of risks the new service will imply. Additionally a plan to mitigate and react to each of these risks must be there. These risks can be technical risks or operational risks. Finally an implementation plan is introduced. This plan gives a general road map for implementing of these new services. Besides all these an action list with time boundaries must be existed to apply more control over the new service implementation life cycle.

\subsubsection{Prioritization}

This step is especially important for those organizations if they have lack of resources and time restricted. This is very important to prioritize the incoming request for new/changed services. Furthermore, prioritization criteria must be existed within the organization and these criteria must be discussed and approved from the business units. After the new service is evaluated, prioritized and selected to be implemented. Implementation should follow the implementation plan presented in the evaluation step. A detailed requirement gathering must be conducted and approved by the requester. After that analysis and design for the new services will start and is much similar to analysis and design in web application development. However, the design must be done very carefully because introducing new services will affect the existing services most of the time therefore impact analysis and risk documents are very helpful in this step. After all these the actual development can start.

\subsubsection{Integration and Testing}

This is an important step for reviewing the impact analysis and risk documents that will help in testing the services and more important for testing of those other services that may impact on the existing services. Therefore defining the "integration architecture" is much helpful in delivering new integrated services more smoothly.

\subsubsection{Deployment and Acceptance}

Once the model is tested it will be handover to the end user or business unit to ensure according to their requirement. If they have any query about the model so it will be revised according to the end users complaints. As mentioned earlier that the presented model is an iterative model and can proudly accept changes any where and at any stage of its development and implementation.

The overall service delivery model can be used for every new service or change request. It will add the new/changed services to the portal service portfolio. It is like a snowball the new/changed services can be added easily in the existing portal at any time whenever required. Finally after presenting all these steps in the proposed model we are strongly recommended that it will be helpful for both the end users and business unit to adopt this iterative model presented in this paper for mature implementation of new portals. 


\section{Conclusion}

The main advantage of this work presented in this paper is an iterative nature of the proposed model. It can accept changes at any stage of its implementation. As mentioned above that portals are never ending project therefore the framework of this model is defined in such a way that it can accept changes and can easily updated according to requirements of organizations at any time when needed. If in case there is no problem in future so we can proudly say that we have implemented the portal successfully.

\section{Future Work}

The model presented in this paper is an iterative nature model and can accept changes any time to be updated whenever required. Due to this property the model can be updated and enhanced with new technology and business requirements over the time for the success of an organization and according to the user satisfactions and requirements.

\section{Acknowledgement}

We would like to thanks the director of KETT, King Saud University for his financial support for this work. We extend our sincere gratitude to the director general of ERP project for his encouraging advices and motivation towards this research work. Finally thanks are also due to all those whom contributed to make this research work successful.

\section{References}

Caro. A., Calero. C., Mendes. E., \& Piattini. M. (2007). A Probabilistic Approach to Web Portal's Data Quality Evaluation. In proceedings: IEEE Conference on Quality of Information and Communication Technology, pp. 143-153.

Chan. M.F.S., \& Chung. W.W.C. (2002). A framework to develop an enterprise information portal for contract manufacturing. International journal of production Economics, Vol.75(2), pp.113-126.

Davydov, M. M. (2001). Corporate Portals and E-Business Integration. McGraw-Hill.

Detlor. B. (2000). The corporate portal as information infrastructure: towards a framework for portal design. International Journal of Information Management, vol. 20(2), pp.91-101.

Georgia. A., Chambers. S., \& Veen. T. V. (2010). New portal implementation. ECP-2006-DILI-510003, Tel Plus, pp- 1-12.

Hazra. T. K. (2002). "Building Enterprise Portals: principles to practice", in Proceedings IEEE International Conference on Software Engineering, pp. 623-633.

IT SMF. (2007). "An Introductory Overview of ITIL ® V3", Published in association with the Best Management Practice Partnership, UK, Pages 56.

Parker. R.C. (1997). Guide to Web Content and Design. MIT Press, New York.

Rahim. M. M. (2007). Identifying Barriers to using Business-to-Employee (B2E) Portals: Some Lessons Learned from an Australian University. In Proceedings: IEEE International Conference on System Sciences, pp. 147a.

Remus, U. (2006). "Critical Success Factors of Implementing Enterprise Portals", In proceeding: IEEE 39th Hawaii International Conference on System Sciences, pp 182a.

Tojib, D. R., Sugianto, L. F., \& Rahim, M. M. (2005). “A New Framework for B2E Portal Development”, In proceeding IEEE international conference on e-technology, e-commerce and e- services, pp. 711-714.

Yon. S. H., \& Daud. R. M. (2008). "Knowledge Management Implementation Model for Community Information Service (Cis) In the Library: A Case of Penang State Library", [Online] Available: http://eprints.ukm.my/132/1/Knowledge_Management_Implementation_Model_For_Community_Information_Se rvice_(CIS)_In_The_Library.pdf, pp 1-7.

Zhu. F., \& Wang. A, Ju. A. (2004). “A framework to develop a university information portal”, In proceedings IEEE international conference on Information Acquisition, pp 506-509. 


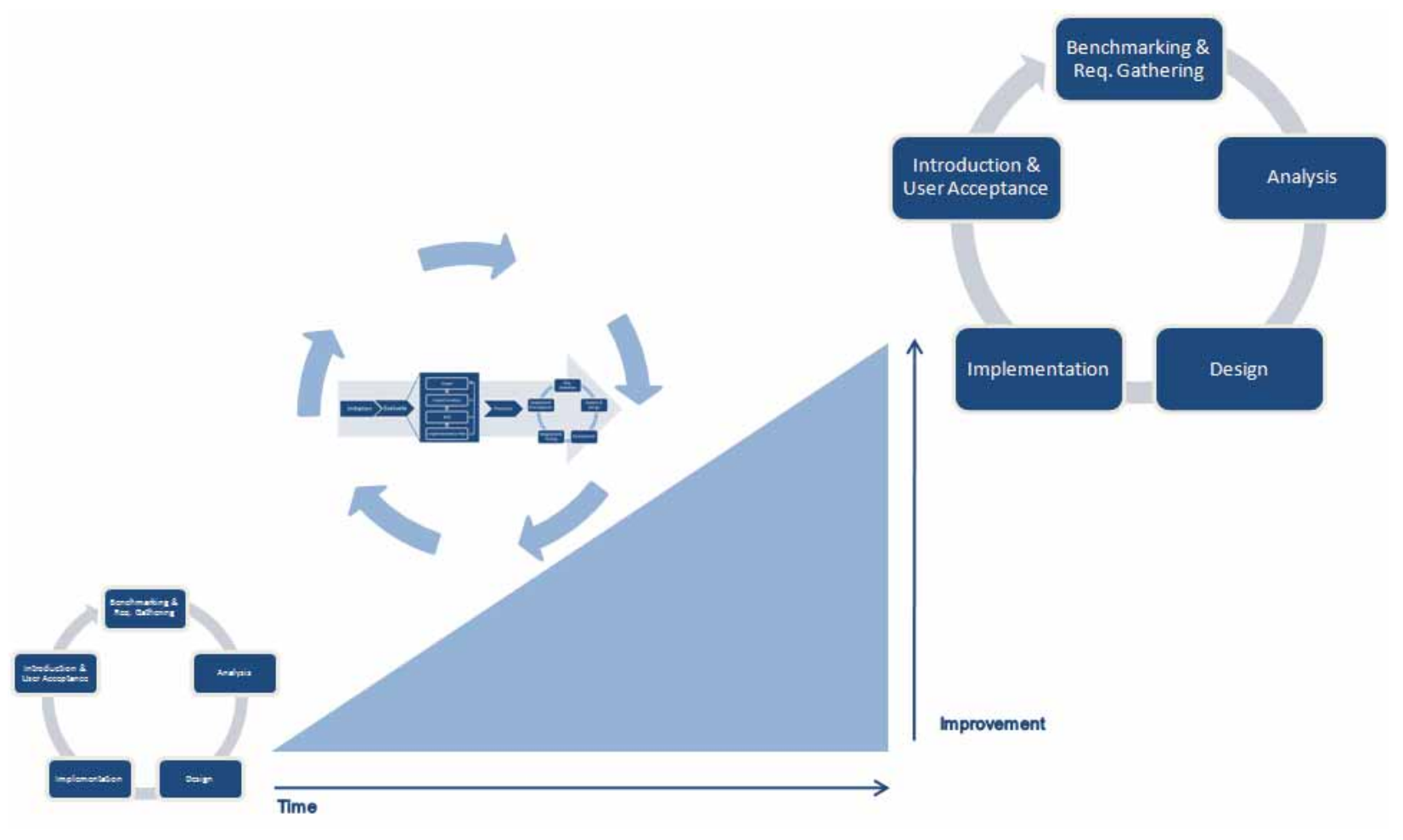

Figure 1. Complete Portal Implementation Model

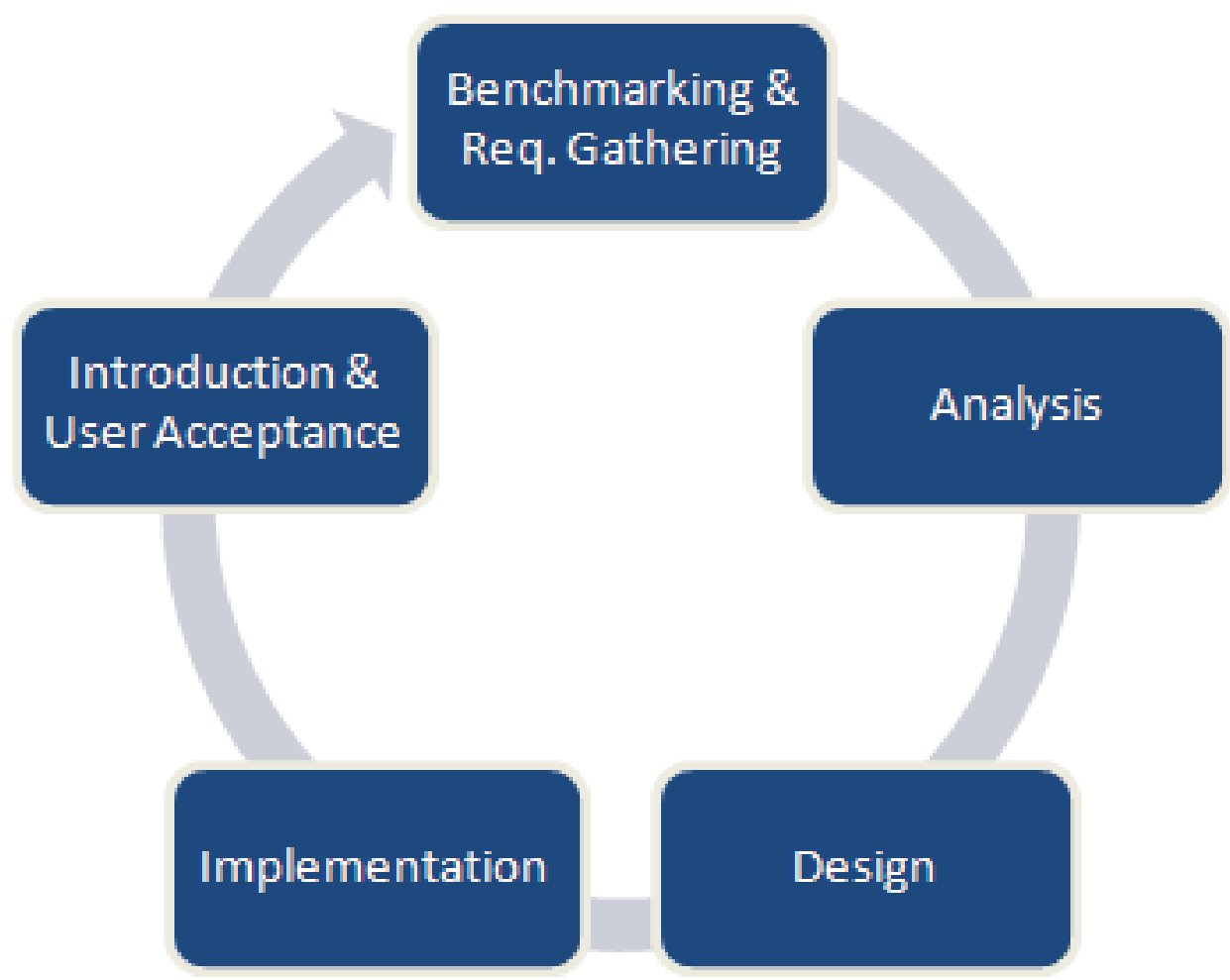

Figure 2. Portal Implementation Model 


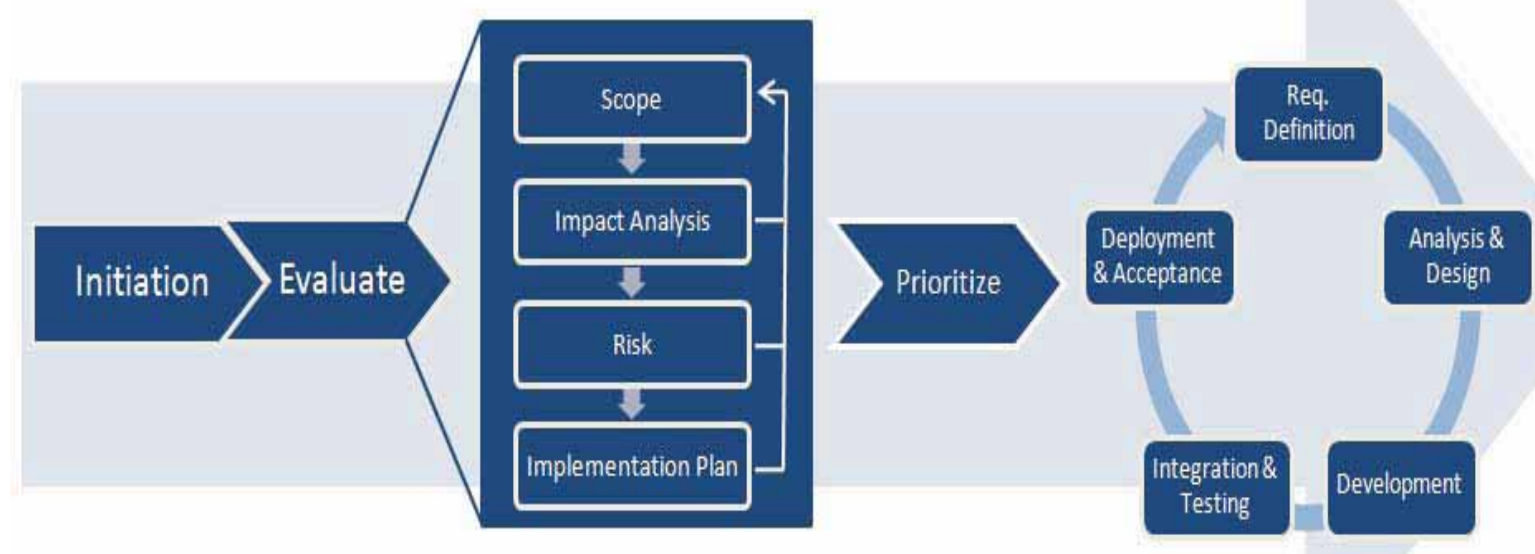

Figure 3. Service Delivery Model 